\title{
ChemComm
}

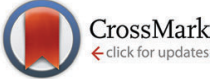

Cite this: Chem. Commun., 2016, 52,677

Received 11th September 2015, Accepted 30th October 2015

DOI: $10.1039 / \mathrm{c} 5 \mathrm{cc} 07629 \mathrm{c}$

www.rsc.org/chemcomm

\section{Connecting mononuclear dysprosium single-molecule magnets to form dinuclear complexes via in situ ligand oxidation $\dagger$}

\author{
Nathan J. Yutronkie, Irina A. Kühne, Ilia Korobkov, Jaclyn L. Brusso* and \\ Muralee Murugesu*
}

\begin{abstract}
$A y_{2}$ complex, exhibiting SMM behaviour, and its $\mathrm{Y}$ analogue were prepared via in situ oxidation of $\mathrm{Py}_{2} \mathrm{TTA}$, a pincer type ligand, followed by dimerisation. This unique metal complexation and subsequent dimerization were followed by solution NMR studies.
\end{abstract}

Since the discovery of the magnet-like behaviour of slow relaxation of the magnetization in individual molecules, Single-Molecule Magnets (SMMs) have emerged as prominent systems in regard to molecular magnetism. ${ }^{1}$ This is primarily due to the fact that these molecules hold tremendous potential towards implementation in quantum computation and memory storage devices. ${ }^{2}$ Over the years, several hundreds of research groups have focused their attention on the synthesis of new SMMs with large energy barriers using various anisotropic $3 \mathrm{~d}$ metal ions. ${ }^{3}$ However, the recent development of lanthanides as ideal candidates for the isolation of high barrier SMMs has shifted synthetic efforts due to the considerable intrinsic magnetic anisotropy of the late $4 \mathrm{f}$ elements. ${ }^{4}$

Although lanthanide-SMMs hold the current record for large anisotropy barriers, significant improvements are necessary for their realization in the aforementioned applications. For instance, inducing magnetic coupling between two $4 \mathrm{f}$ ions remains a major challenge due to the core nature of the $4 \mathrm{f}$ orbitals. In addition, controlling the symmetry, coordination geometry and the crystal field effects are not trivial. This therefore necessitates the design, synthesis and study of novel systems. When it comes to developing new SMMs, ligand design is critical. To that end, ligands must be efficient chelates while also harnessing the intrinsic anisotropy of lanthanide ions. ${ }^{5}$ Ligands that can also act as bridging units between metal centres are particularly attractive as they can also provide potential magnetic exchange pathways often termed super-exchange. In most

Department of Chemistry and Biomolecular Sciences, University of Ottawa, 10 Marie Curie, Ottawa, ON K1N 6N5 Canada. E-mail: jbrusso@uottawa.ca, m.murugesu@uottawa.ca

$\dagger$ Electronic supplementary information (ESI) available: Synthetic procedures, crystallographic details and magnetic studies. CCDC 1423127 and 1423128. For ESI and crystallographic data in CIF or other electronic format see DOI: 10.1039/ c5cc07629c cases, ligands are carefully chosen for these chelating and/or bridging properties. In that regard, $2,2^{\prime} ; 6^{\prime}, 2^{\prime \prime}$-terpyridine (terpy) is a well known tridentate chelating ligand that has been used for several decades for encapsulating metal ions. However, terpy does not provide any possibilities for bridging metal ions. In contrast, 3,5-bis(2-pyridyl)-4-hydro-1,2,4,6-thiatriazine ( $\left.\mathrm{Py}_{2} \mathrm{TTAH}\right)$, an inherently redox active pincer-type ligand is highly versatile. Recently we reported the versatility of the $\mathrm{Py}_{2} \mathrm{TTAH}$ ligand that can act as an anionic unit upon deprotonation. Alternatively, $\mathrm{Py}_{2} \mathrm{TTAH}$ can be oxidized to generate a neutral radical, which can then be oxidized to form 1-oxo-3,5-bis(2-pyridyl)-4-hydro-1,2,4,6-thiatriazine (1-oxo$\mathrm{Py}_{2}$ TTAH); all while retaining its stable coordination pocket. ${ }^{6}$ Therefore, $\mathrm{Py}_{2} \mathrm{TTAH}$ is an ideal ligand system to explore in the coordination chemistry of lanthanide ions.

The synthesis of SMMs based on coordination chemistry relies on a self-assembly process. In this approach, energetically favourable coordination complexes are formed and subsequently studied through single-crystal X-ray diffraction and magnetometry in order to establish magneto-structural correlations. Little importance is typically given to the self-assembly process as the reaction intermediates are often hard to isolate or study since these reactions involve several ingredients in a one-pot synthesis. However, if the self-assembly process can be monitored and studied, invaluable information on the complex formation can be achieved. This can subsequently be applied to the synthesis of targeted molecules. With this in mind, we have focused our attention on the synthesis of $\mathrm{Py}_{2}$ TTA based lanthanide SMMs, not only for their magnetic behaviour but also to investigate their self-assembly process. Herein we report the synthesis, isolation and study of $\left[\mathrm{Dy}_{2}\left(1-\mathrm{oxo}-\mathrm{Py}_{2} \mathrm{TTA}\right)_{2}\left(\mathrm{NO}_{3}\right)_{4}\left(\mathrm{H}_{2} \mathrm{O}\right)_{2}\right] \cdot \mathrm{CH}_{3} \mathrm{CN}(3 \mathbf{a})$, exhibiting SMM properties. In addition, its yttrium analogue is reported in order to elucidate the self-assembly of our SMM via NMR studies.

Reaction of Dy( $\left.\mathrm{NO}_{3}\right)_{3} \cdot 6 \mathrm{H}_{2} \mathrm{O}$ (1 equiv.) with $\mathrm{Py}_{2} \mathrm{TTAH}$ (1 equiv.) in $\mathrm{CH}_{3} \mathrm{CN}$ yielded a dark-purple solution which turns clear colourless within one hour (Scheme 1 inset). After 3 hours, the formation of pale yellow rectangular shaped crystals of $\mathbf{3 a}$ resulted in $60 \%$ yield. The drastic change in colour of the reaction 


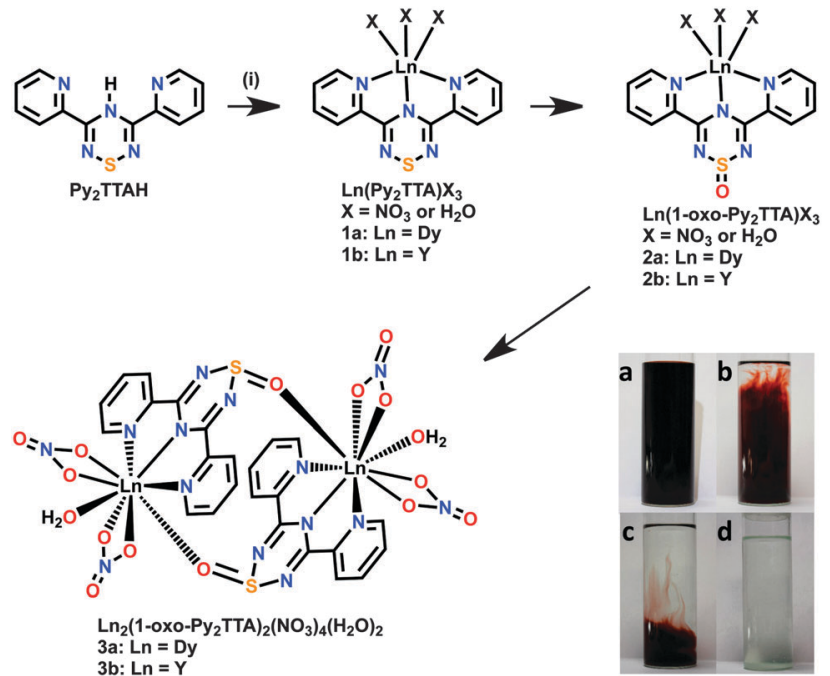

Scheme 1 Synthesis of complexes $\mathbf{3 a}$ and $\mathbf{3 b}$. Reagents and conditions: (i) $\mathrm{Ln}\left(\mathrm{NO}_{3}\right)_{3} \cdot 6 \mathrm{H}_{2} \mathrm{O}, \mathrm{CH}_{3} \mathrm{CN}$, RT. Inset: Evolution of the reaction mixture at (a) $T=0 \mathrm{~min}$; (b) $T=80 \mathrm{~min}$; (c) $T=90 \mathrm{~min}$; (d) $T=100 \mathrm{~min}$.

mixture indicates a change in the "redox" chemistry of the ligand upon coordination. This is further evidenced by the single-crystal $\mathrm{X}$-ray structure, which indicates that metal assisted oxidation of the ligand occurs (vide infra). It is noteworthy that an increase in metal concentration (e.g., from 1 to 2 equivalents) in the reaction mixture accelerates the rate of the change in colour. In addition, the size and shape of the reaction vessel influence the rate of the reaction. Based on these observations, it is clear that some interesting redox chemistry is occurring, as $\mathrm{Py}_{2} \mathrm{TTAH}$ is surprisingly robust with a high tolerance towards aqueous, basic, and thermal conditions. Its only instability appears to be under acidic conditions, in which the thiatriazine ring opens and regenerates an $N$-bridgehead-1,2,5-thiadiazolium salt. ${ }^{7}$ Furthermore, oxidation of $\mathrm{Py}_{2} \mathrm{TTAH}$ in the absence of metals is not achievable. For example, bubbling $\mathrm{O}_{2}$ gas through solutions of $\mathrm{Py}_{2} \mathrm{TTAH}$ in $\mathrm{MeOH}, \mathrm{MeCN}$ (wet and dry) and DCM left $\mathrm{Py}_{2}$ TTAH intact (i.e., no oxidation occurred). If, however, the ligand is coordinated to a metal ion, oxidation becomes more feasible, as has been observed in previous coordination studies employing this ligand system. ${ }^{6}$

Since $\mathrm{Py}_{2}$ TTA can exist as a neutral radical in solution, the generation of the oxide may be attributed to the generation of the radical, which is known to be susceptible to oxidation. ${ }^{8}$ Alternatively, the generation of the oxide may occur following coordination to the metal ion, which pulls electron density of the anionic charge towards the metal centre leaving the sulphur atom of the TTA ring susceptible to oxidation. In order to elucidate the reaction process, time dependent ${ }^{1} \mathrm{H}$ NMR studies were carried out on the in situ reaction between $\mathrm{Y}\left(\mathrm{NO}_{3}\right)_{3} \cdot 6 \mathrm{H}_{2} \mathrm{O}$ ( 2 equiv.) and $\mathrm{Py}_{2} \mathrm{TTAH}$ (1 equiv.) in $\mathrm{CD}_{3} \mathrm{CN}$. The choice of $\mathrm{Y}\left(\mathrm{NO}_{3}\right)_{3} \cdot 6 \mathrm{H}_{2} \mathrm{O}$ over $\mathrm{Dy}\left(\mathrm{NO}_{3}\right)_{3} \cdot 6 \mathrm{H}_{2} \mathrm{O}$ for the NMR studies was due to the diamagnetic nature of yttrium, which would enable the determination of the formation of a radical intermediate (e.g., if a paramagnetic signal was observed this could be attributed to the generation of the $\mathrm{Py}_{2} \mathrm{TTA}$ radical). Conversely, if diamagnetic intermediates are formed, using yttrium in place of dysprosium enables identification of the intermediates via NMR spectroscopy. In order to correlate these results with the reaction observed between $\mathrm{Dy}\left(\mathrm{NO}_{3}\right)_{3} \cdot 6 \mathrm{H}_{2} \mathrm{O}$ and $\mathrm{Py}_{2} \mathrm{TTAH}$, in addition to similar physical properties of the reaction (i.e., bleaching of the reaction mixture), $\mathrm{X}$-ray analysis confirmed the generation of isostructural $\left[\mathrm{Y}_{2}\left(1-\mathrm{oxo}-\mathrm{Py}_{2} \mathrm{TTA}\right)_{2}\left(\mathrm{NO}_{3}\right)_{4}\left(\mathrm{H}_{2} \mathrm{O}\right)_{2}\right] \cdot \mathrm{CH}_{3} \mathrm{CN}$ (3b, see ESI, $†$ Fig. S1).

Time dependent ${ }^{1} \mathrm{H}$ NMR studies, which are summarized in Fig. 1, reveal that the reaction mixture initially consists solely of the unreacted $\mathrm{Py}_{2}$ TTAH starting material. After 15-20 min, four additional pyridyl peaks begin to emerge, which is attributed to the generation of a yttrium coordinated $\mathrm{Py}_{2}$ TTA ligand intermediate (i.e., $\left.\mathbf{1 b} ; \mathrm{Y}\left(\mathrm{Py}_{2} \mathrm{TTA}\right) \mathrm{X}_{3}\right)$. Within $5-10 \mathrm{~min}$ of the observation of the first intermediate, a second compound also exhibiting a pattern consistent with four pyridyl peaks appears, which is postulated to be the oxidized ligand, 3,5-bis(pyridyl)-1oxo-1,2,4,6-thiatriazine (1-oxo-Py ${ }_{2}$ TTA) coordinated to yttrium (i.e., 2b; $\mathrm{Y}\left(1-\mathrm{oxo}-\mathrm{Py}_{2} \mathrm{TTA}\right) \mathrm{X}_{3}$ ). After $60 \mathrm{~min}, \mathrm{Py}_{2} \mathrm{TTAH}, \mathrm{Y}\left(\mathrm{Py}_{2} \mathrm{TTA}\right) \mathrm{X}_{3}$ and $\mathrm{Y}\left(1-\mathrm{Oxo}-\mathrm{Py}_{2} \mathrm{TTA}\right) \mathrm{X}_{3}$ are all present in the solution. After $90 \mathrm{~min}$, we begin to see the depletion of $\mathrm{Py}_{2} \mathrm{TTAH}$ and broadening of the NMR peaks, which is attributed to precipitation of the dimer within the NMR tube. Following the complete consumption of $\mathrm{Py}_{2}$ TTAH (6 $\mathrm{h}$ spectrum) the $\mathrm{N}-\mathrm{H}$ peaks no longer exist, providing evidence for these assignments as metal coordinated ligands. Comparison of the peak shifts with that of unreacted $\mathrm{Py}_{2} \mathrm{TTAH}$ and the 1-oxo-Py $\mathrm{P}_{2} \mathrm{TTAH}$ (prepared via oxidation of the radical), coupled with the formation of the dimer (which precipitates out of solution), further supports these assignments.

Due to the isostructural nature of complexes $\mathbf{3 a}$ and $\mathbf{3 b}$, only the dysprosium analogue is discussed below. The asymmetric unit of the centrosymmetric structure of $\mathbf{3 a}$ is composed of a Dy III ion with a nine-coordinate environment adopting a distorted muffin geometry (Fig. 2). ${ }^{9}$ The tridentate terpyridine-like coordination pocket of the $\mathrm{Py}_{2}$ TTA ligand binds to the metal centre via $\mathrm{N} 1, \mathrm{~N} 4$ and $\mathrm{N} 5$ donors while oxygen atoms $(\mathrm{O} 2, \mathrm{O} 3$, $\mathrm{O} 5, \mathrm{O} 6)$ from two nitrate anions and a water molecule (O8) occupy the primary coordination environment. The remaining single coordination site is occupied by an oxygen atom (O1a) from the oxidized $\mathrm{S}=\mathrm{O}$ group of the neighbouring $\mathrm{Py}_{2} \mathrm{TTA}$ ligand. This $\mathrm{S}=\mathrm{O}$ group plays an integral role in the dimerization and formation of the dinuclear molecule. The intramolecular Dy-Dy distance of $7.09 \AA$ (Fig. S2, ESI $\dagger$ ) is relatively long compared to the reported dinuclear complexes; however, weak intramolecular magnetic interactions cannot be ignored for highly anisotropic Dy ${ }^{\mathrm{III}}$ ions. ${ }^{10}$ It is interesting to note that there are no short contacts or hydrogen bonding between the asymmetric units; only the $\mathrm{S}=\mathrm{O}$ bridges hold the dinuclear molecules together. Close inspection of the packing arrangement reveals that the molecules are well aligned with each other with the closest inter-metal distance being 6.76 A (Fig. S2, ESI $†$ ).

In order to elucidate the magnetic properties of the paramagnetic complex 3a, direct current (dc) and alternating current (ac) magnetic susceptibility measurements were performed using a squid magnetometer. The dc susceptibility measurements at 1000 Oe (Fig. S3, ESI $\dagger$ ) reveal a room temperature $\chi T$ value of 

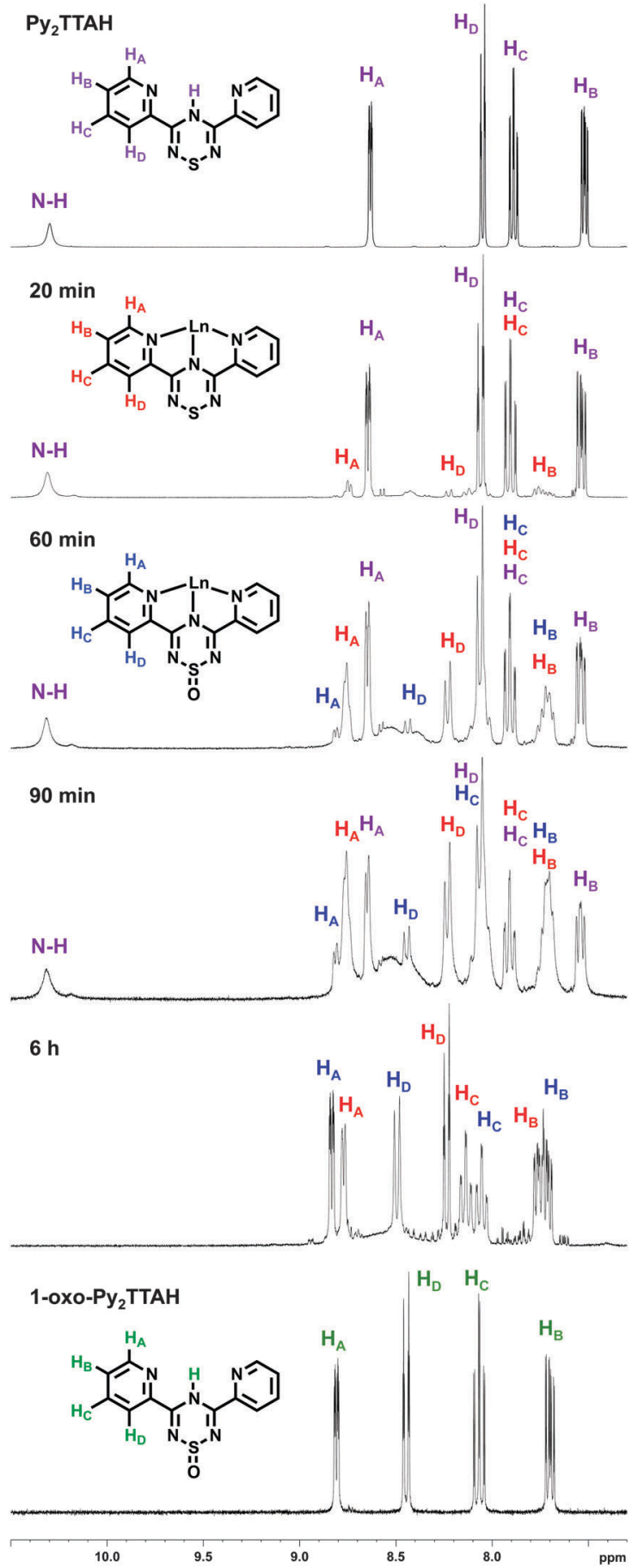

Fig. 1 Time dependent ${ }^{1} \mathrm{H}$ NMR studies on the in situ reaction between $\mathrm{Y}\left(\mathrm{NO}_{3}\right)_{3} \cdot 6 \mathrm{H}_{2} \mathrm{O}$ (2 equiv.) and $\mathrm{Py}_{2} \mathrm{TTAH}$ (1 equiv.) in $\mathrm{CD}_{3} \mathrm{CN}\left(1 \mathrm{~mL}, 6.4 \times 10^{-2} \mathrm{M}\right)$.

$27.97 \mathrm{~cm}^{3} \mathrm{~K} \mathrm{~mol}^{-1}$ consistent with the expected value of $28.34 \mathrm{~cm}^{3} \mathrm{~K} \mathrm{~mol}^{-1}$ for two non-interacting Dy ${ }^{\mathrm{III}}$ ions $(S=5 / 2$, $\left.L=5,{ }^{6} \mathrm{H}_{15 / 2}, g=4 / 3\right)$. Upon lowering the temperature, the $\chi T$ product decreases gradually to reach a minimum value of $18.80 \mathrm{~cm}^{3} \mathrm{~K} \mathrm{~mol}^{-1}$ at $1.8 \mathrm{~K}$. Such a negative deviation suggests the existence of weak antiferromagnetic interactions between metal ions and/or the presence of magnetic anisotropy. Intraand intermolecular distances (7.09 and $6.76 \AA$, respectively)

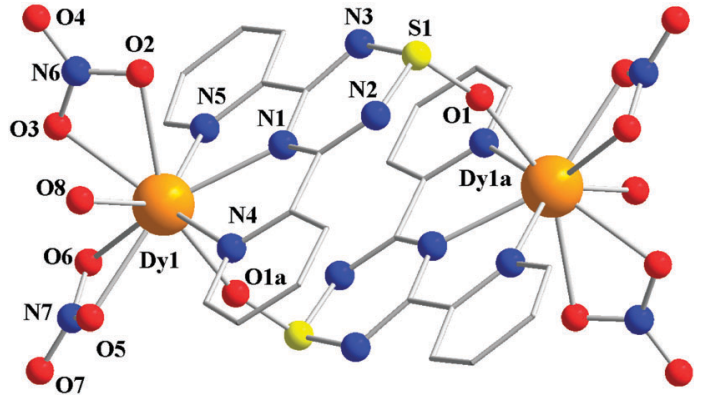

Fig. 2 Partially labelled molecular X-ray structure of the centrosymmetric dinuclear complex $3 a$. Hydrogen atoms are omitted for clarity.

suggest that at this applied field interactions between the ions are likely rather small, if not negligible, due to the core nature of the $4 \mathrm{f}$ ions. ${ }^{11}$ Therefore, it is reasonable to attribute the decrease of the $\chi T$ product to the magnetic anisotropy of the $\mathrm{Dy}^{\mathrm{III}}$ ions.

Recent studies have shown a nine-coordinate environment around the Dy ion that can provide non-negligible magnetic anisotropy to a molecular system if an ideal ligand field is present. ${ }^{9}$ Here, the two nitrate ions around the metal centre play an important electron withdrawing effect by promoting higher degeneracy of the $4 \mathrm{f}$ orbitals subsequently leading to enhanced spin-orbit coupling. ${ }^{12}$ In order to further confirm the magnetic anisotropy, magnetization measurements were performed (Fig. S4, ESI $\dagger$ ). The magnetization plot $M$ vs. $H / T$ shows field dependence of the magnetization that does not saturate at low temperatures and high magnetic fields indicating the presence of magnetic anisotropy and/or low lying excited states in this system. Moreover, the non-superimposition of the iso-temperature lines indicates magnetic anisotropy.

To further explore the possibility of SMM behaviour, ac magnetic susceptibility measurements were carried out under a zero dc field. The characteristic frequency dependent out-ofphase signal was not observed; this can be attributed to significant quantum tunnelling of the magnetization (QTM) often observed in lanthanide SMMs, which diminishes the relaxation barriers. Such QTM can be reduced upon application of a small static field. In order to determine the optimum dc field, ac susceptibility measurements at various static fields (250-3000 Oe) were performed at $2 \mathrm{~K}$ (Fig. S5, ESI $\dagger$ ). The out-ofphase data clearly exhibit an optimum dc field (the field at which the minimum of characteristic frequency is observed, Fig. S6, ESI $\dagger$ ) of 750 Oe, where the QTM is minimized. Ac measurements at this optimum field reveal a full frequency dependent peak below $5 \mathrm{~K}$ between 0.1 and $1000 \mathrm{~Hz}$ (Fig. 3) indicative of field-induced SMM behaviour. Analysis of the data using the Arrhenius law $\left[\tau=\tau_{0} \exp \left(U_{\text {eff }} / k_{\mathrm{B}} T\right)\right]$ gave a calculated relaxation barrier of $U_{\text {eff }}=19 \mathrm{~K}$ and a $\tau_{0}$ value of $2.0 \times 10^{-7} \mathrm{~s}$ for the thermally activated regime (Fig. S7, ESI $\dagger$ ). The observed barrier is relatively small as a result of the QTM. It is noteworthy that the presence of a peak shoulder around $1 \mathrm{~Hz}$ can be observed in Fig. 3. The intensity of the peak shoulder grows to become a full peak when the applied static field is increased to 2500 Oe and diminishes at smaller fields such as 250 Oe 

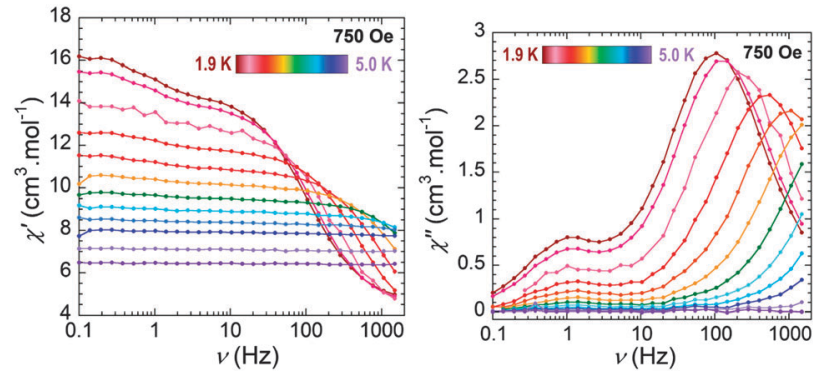

Fig. 3 Frequency dependence of the in-phase $\chi^{\prime}$ (left) and out-of-phase $\chi^{\prime \prime}$ (right) ac susceptibility signals under 750 Oe dc field for $3 a$ at the indicated temperatures.

(Fig. S5, ESI $\dagger$ ). Moreover, ac data collected at the applied static field of 2500 Oe exhibit this peak around $1 \mathrm{~Hz}$, which does not shift (Fig. S8, ESI $\dagger$ ). Such behaviour can arise from large fieldinduced intermolecular interactions rather than arising from the molecular origin. ${ }^{13}$ This is also not completely surprising given the fact that the closest inter-metal distance of $6.76 \AA$ is shorter than the intramolecular Dy-Dy distance.

In conclusion, we have successfully isolated a dinuclear dysprosium complex and its yttrium analogue via in situ metalassisted ligand oxidation of our pincer type $\mathrm{Py}_{2}$ TTA followed by dimerization. This unique metal complexation was carefully probed through solution NMR studies, which clearly demonstrates the ability of the $\mathrm{Py}_{2}$ TTA ligand to oxidize, and form the 1-oxo-Py ${ }_{2}$ TTA upon metal coordination. Subsequently, the oxidized ligand coordinates to the oxophilic lanthanide ion thus forming discrete dinuclear molecules.

The paramagnetic Dy analogue displays field-induced singlemolecule magnet behaviour where the origin is attributed to the single-ion anisotropy of the dysprosium ion. Although $\mathbf{3 a}$ is structurally a dinuclear molecule, due to the large intramolecular separation, it acts as a mononuclear SMM. Higher applied dc fields during the ac measurements indicate the presence of a secondary relaxation process that can be attributed to intermolecular interactions rather than being molecular in origin. This study provides a methodology for probing/visualizing reactions that can be used to understand the nature of self-assemblies and their driving forces.

\section{Notes and references}

1 G. Christou, D. Gatteschi, D. N. Hendrickson and R. Sessoli, MRS Bull., 2000, 25, 66-71.

2 L. Bogani and W. Wernsdorfer, Nat. Mater., 2008, 7, 179-186.

3 (a) T. C. Stamatatos, D. Foguet-Albiol, C. C. Stoumpos, C. P. Raptopoulou, A. Terzis, W. Wernsdorfer, S. P. Perlepes and G. Christou, J. Am. Chem. Soc., 2005, 127, 15380-15381; (b) C. J. Milios, A. Vinslava, W. Wernsdorfer, S. Moggach, S. Parsons, S. P. Perlepes, G. Christou and E. K. Brechin, J. Am. Chem. Soc., 2007, 129, 2754-2755; (c) G. Aromi and E. K. Brechin, Single-Molecule Magnets and Related Phenomena, 2006, 122, 1-67; (d) M. Murrie, Chem. Soc. Rev., 2010, 39, 1986-1995; (e) R. Sato, K. Suzuki, T. Minato, M. Shinoe, K. Yamaguchi and N. Mizuno, Chem. Commun., 2015, 51, 4081-4084; $(f)$ C. Lampropoulos, C. Koo, S. O. Hill, K. Abboud and G. Christou, Inorg. Chem., 2008, 47, 11180-11190.

4 (a) J. K. Tang, I. Hewitt, N. T. Madhu, G. Chastanet, W. Wernsdorfer, C. E. Anson, C. Benelli, R. Sessoli and A. K. Powell, Angew. Chem., Int. Ed., 2006, 45, 1729-1733; (b) N. Ishikawa, M. Sugita, T. Ishikawa, S. Koshihara and Y. Kaizu, J. Am. Chem. Soc., 2003, 125, 8694-8695; (c) P.-H. Lin, T. J. Burchell, R. Clerac and M. Murugesu, Angew. Chem., Int. Ed., 2008, 47, 8848-8851; (d) S. Cardona-Serra, J. M. Clemente-Juan, E. Coronado, A. Gaita-Arino, A. Camon, M. Evangelisti, F. Luis, M. J. Martinez-Perez and J. Sese, J. Am. Chem. Soc., 2012, 134, 14982-14990.

5 (a) J. D. Rinehart and J. R. Long, Chem. Sci., 2011, 2, 2078-2085; (b) C. Aronica, G. Pilet, G. Chastanet, W. Wernsdorfer, J.-F. Jacquot and D. Luneau, Angew. Chem., Int. Ed., 2006, 45, 4659-4662; (c) P.-H. Lin, W.-B. Sun, M.-F. Yu, G.-M. Li, P.-F. Yan and M. Murugesu, Chem. Commun., 2011, 47, 10993-10995.

6 K. L. M. Harriman, A. A. Leitch, S. A. Stoian, F. Habib, J. L. Kneebone, S. I. Gorelsky, I. Korobkov, S. Desgreniers, M. L. Neidig, S. Hill, M. Murugesu and J. L. Brusso, Dalton Trans., 2015, 44, 10516-10523.

7 A. A. Leitch, I. Korobkov, A. Assoud and J. L. Brusso, Chem. Commun., 2014, 50, 4934-4936.

8 N. J. Yutronkie, A. A. Leitch, I. Korobkov and J. L. Brusso, Cryst. Growth Des., 2015, 15, 2524-2532.

9 A. K. Mondal, S. Goswami and S. Konar, Dalton Trans., 2015, 44, 5086-5094.

10 F. Habib and M. Murugesu, Chem. Soc. Rev., 2013, 42, 3278-3288.

11 R. A. Layfield, J. J. W. McDouall, S. A. Sulway, F. Tuna, D. Collison and R. E. P. Winpenny, Chem. - Eur. J., 2010, 16, 4442-4446.

12 F. Habib, G. Brunet, V. Vieru, I. Korobkov, L. F. Chibotaru and M. Murugesu, J. Am. Chem. Soc., 2013, 135, 13242-13245.

13 F. Habib, I. Korobkov and M. Murugesu, Dalton Trans., 2015, 44, 6368-6373. 